\title{
Horizontal and vertical structure of the Eyjafjallajökull ash cloud over the UK: a comparison of airborne lidar observations and simulations
}

\author{
A. L. M. Grant ${ }^{1}$, H. F. Dacre ${ }^{1}$, D. J. Thomson ${ }^{2}$, and F. Marenco ${ }^{2}$ \\ ${ }^{1}$ Department of Meteorology, University of Reading, Reading, UK \\ ${ }^{2}$ Met Office, Exeter, UK \\ Correspondence to: H. F. Dacre (h.f.dacre@ reading.ac.uk)
}

Received: 20 February 2012 - Published in Atmos. Chem. Phys. Discuss.: 10 April 2012

Revised: 22 August 2012 - Accepted: 27 October 2012 - Published: 5 November 2012

\begin{abstract}
During April and May 2010 the ash cloud from the eruption of the Icelandic volcano Eyjafjallajökull caused widespread disruption to aviation over northern Europe. The location and impact of the eruption led to a wealth of observations of the ash cloud were being obtained which can be used to assess modelling of the long range transport of ash in the troposphere. The UK FAAM (Facility for Airborne Atmospheric Measurements) BAe-146-301 research aircraft overflew the ash cloud on a number of days during May. The aircraft carries a downward looking lidar which detected the ash layer through the backscatter of the laser light. In this study ash concentrations derived from the lidar are compared with simulations of the ash cloud made with NAME (Numerical Atmospheric-dispersion Modelling Environment), a general purpose atmospheric transport and dispersion model.

The simulated ash clouds are compared to the lidar data to determine how well NAME simulates the horizontal and vertical structure of the ash clouds. Comparison between the ash concentrations derived from the lidar and those from NAME is used to define the fraction of ash emitted in the eruption that is transported over long distances compared to the total emission of tephra. In making these comparisons possible position errors in the simulated ash clouds are identified and accounted for.

The ash layers seen by the lidar considered in this study were thin, with typical depths of $550-750 \mathrm{~m}$. The vertical structure of the ash cloud simulated by NAME was generally consistent with the observed ash layers, although the layers in the simulated ash clouds that are identified with observed ash layers are about twice the depth of the observed layers. The
\end{abstract}

structure of the simulated ash clouds were sensitive to the profile of ash emissions that was assumed. In terms of horizontal and vertical structure the best results were obtained by assuming that the emission occurred at the top of the eruption plume, consistent with the observed structure of eruption plumes. However, early in the period when the intensity of the eruption was low, assuming that the emission of ash was uniform with height gives better guidance on the horizontal and vertical structure of the ash cloud.

Comparison of the lidar concentrations with those from NAME show that $2-5 \%$ of the total mass erupted by the volcano remained in the ash cloud over the United Kingdom.

\section{Introduction}

The eruption of the Icelandic volcano Eyjafjallajökull during April and May 2010 lead to the widespread disruption of air travel throughout Europe due to the hazard posed to aircraft by volcanic ash. At various times during this period parts of European airspace were closed, leading to significant financial losses by airlines and leaving millions of passengers stranded throughout the world.

During the eruption the London Volcanic Ash Advisory Centre (VAAC) issued forecasts of the location of the ash cloud. These forecasts were based on the NAME (Numerical Atmospheric-dispersion Modelling Environment) model (Jones et al., 2007) adjusted in the light of satellite and ground-based observations. NAME is a Lagrangian particle model that uses time varying wind fields to calculate 
the trajectories of particles originating at the position of the volcano to determine where the volcanic ash cloud is transported. Webster et al. (2012) give details about the forecasting of the ash clouds using NAME during the eruption.

A major uncertainty in modelling volcanic ash clouds with volcanic ash transport and dispersion (VATD) models, such as NAME, is the specification of the eruption source parameters (ESP). A VATD model needs information on basic parameters such as the height of the eruption plume, the mass eruption rate and the vertical distribution of the emitted mass. The sensitivity of predictions of ash dispersal to the emission profile has been investigated by Webley et al. (2009) for the August 1992 eruption of Mount Spurr. Their study found that the areal extent of the simulated ash cloud was sensitive to assumptions about the emission profile, with the best agreement between the simulations and satellite observations of the extent of the ash cloud obtained using emission profiles which have releases at all heights within the eruption column.

Eckhardt et al. (2008) and Kristiansen et al. (2010) describe a data assimilation approach to obtain the emission profile of sulphur dioxide for the eruptions of Jebel el Tair and Kasatochi respectively using satellite retrievals of total column sulphur dioxide and a VATD model. Recently Stohl et al. (2011) and Kristiansen et al (2012) have extended this approach to volcanic ash, using data from SEVIRI (Spinning Enhanced Visible Infra-Red Imager) to estimate the vertical distribution and magnitude of the emissions during the Eyjafjallajökull eruption.

An alternative to the satellite inversion approach for estimating the volcanic emissions is to use empirical relationships between the mass eruption rate (MER) and plume height (Sparks et al., 1997; Mastin et al., 2009). This was the approach used by the London VAAC during the eruption and the subsequent eruption of Grimsvötn in 2011 (Webster et al., 2012). Much of the ash in the eruption plume falls out close to the volcano forming the tephra blanket and to estimate concentrations of ash at long ranges an estimate of the fraction of the ash that survives early fall out is needed. Previous estimates this fraction range from $0.05 \%$ to $10 \%$ (Mastin et al., 2009)

This study uses estimates of ash concentrations obtained around the UK by the FAAM (Facility for Airborne Atmospheric Measurements) BAe-146 aircraft. The ash concentrations were estimated from lidar backscatter profiles measured during five flights in May 2010. Comparisons of the horizontal and vertical structure of the ash cloud obtained from the NAME model are described and estimates of the fine ash fraction for the Eyjafjallajökull eruption are made.

\section{Model}

NAME is a Lagrangian particle trajectory model that is designed for use in a range of dispersion modelling applications (Jones et al., 2007; Webster et al., 2012). Particles are released at the source, which in this case is the volcanic eruption plume. Each of the particles represents a mass of volcanic ash. Their trajectories are calculated using analysis wind fields, with a temporal resolution of $3 \mathrm{~h}$, obtained from the global version of the Met Office Unified Model. The model particles are assumed to be carried along by the wind with the effects of turbulence represented by using stochastic perturbations to the trajectories derived from a semi-empirical turbulence parameterisation. NAME also includes treatments of sedimentation and dry and wet deposition (Dacre et al. (2011) for further details). Ash concentrations are computed by summing the mass of particles in model grid boxes, which are $0.374^{\circ}$ in latitude by $0.5625^{\circ}$ in longitude in the horizontal and $200 \mathrm{~m}$ in the vertical, over one hour. The concentration is obtained by dividing the total mass by the volume of the grid box.

Rose et al. (2000) identify three stages in the evolution of volcanic ash clouds. In the first few hours large particles fall out close to the volcano, forming the proximal tephra blanket. This is followed by a period, typically lasting about $24 \mathrm{~h}$, in which the mass in the ash cloud decreases with time, probably due to particle aggregation and subsequent fall out of the aggregates. A large fraction of the erupted mass is removed from the ash cloud during these two phases. Subsequent removal of ash is mainly due to meteorological processes and deposition. NAME does not represent any of the microphysical processes, such as aggregation, that occur within the volcanic ash cloud, although it does have representations of particle sedimentation as well as wet and dry deposition.

The removal of ash by sedimentation depends on the size distribution of the ash particles. In situ observations of the ash cloud by the FAAM aircraft over and around the UK show that particles were generally less than $10 \mu \mathrm{m}$ in diameter (Johnson et al., 2011) in the Eyjafjallajökull ash cloud. Sedimentation of particles with diameters less than $10 \mu \mathrm{m}$ has a small effect on the column mass of ash for travel times of 24 to $80 \mathrm{~h}$ that are relevant in this study. This has been determined by testing the sensitivity of the results to different particle sizes (Dacre et al., 2012). Because of this the evolution of the particle size distribution in the ash cloud due to sedimentation has been neglected by setting the particle size to $3 \mu \mathrm{m}$.

Comparing the lidar observation with NAME an effective source strength for the fine ash particles which formed the ash layers seen by the lidar can be estimated. This effective source strength represents the mass eruption rate of those ash particles that are not removed from the cloud close to the volcano.

A number of relationships between the total MER and the rise height of the eruption plume (i.e. the height of the top of the eruption plume relative to the height of the volcano) have been published (Sparks et al., 1997; Mastin et al., 2009). In the present simulations the relationship between the height 


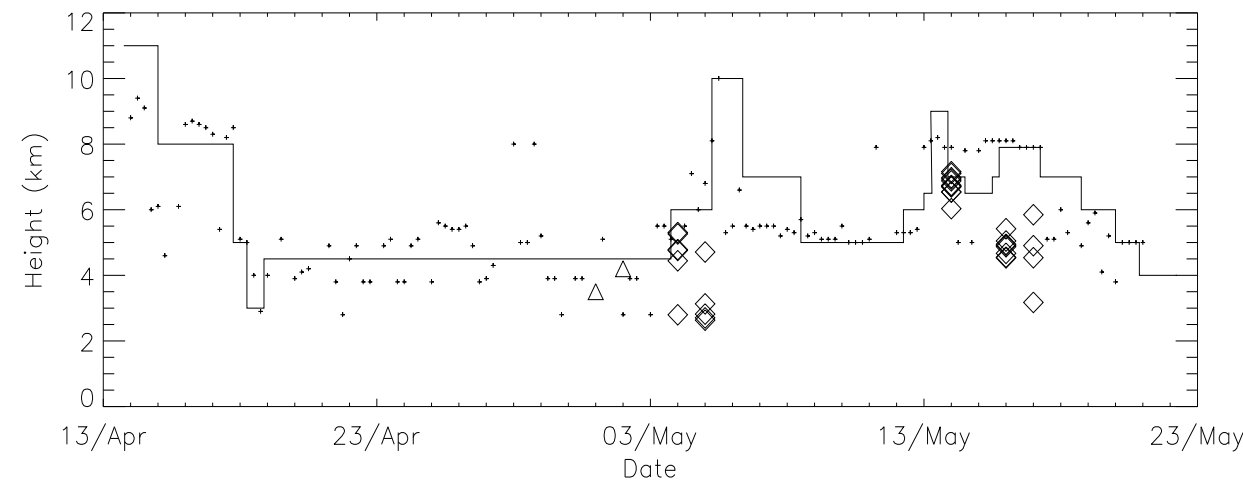

Fig. 1. Timeseries of the height of the eruption plume above sea level. Height of the eruption plume used in NAME simulations (solid line), maximum heights detected by radar (small crosses) taken from Arason et al. (2011), heights of ash layers observed by FAAM aircraft (diamonds), heights of ash layers observed by the DLR Falcon taken from Schumann et al. (2011) (triangles).

of the eruption plume and the MER is taken to be,

$M=140.8 H^{4.15}$

where $H$ is the height of the eruption plume above the volcano summit in kilometres and $M$ is the rate of mass emission in kilogrammes per second (Webster et al., 2012). This relationship is based on a fit to the thresholds in the lookup table designed by NOAA for the VAFTAD model (Heffter and Stunder, 1993) and calibrated by the 'Mastin' curve to give the emission rate as a function of plume height as described by Dacre et al. (2011). For the eruption plume heights relevant to the Eyjafjallajökull eruption the MER estimated from Eq. (1) is within $15 \%$ of estimates based on the relationships proposed by Sparks et al. (1997) and Mastin et al. (2009). Mastin et al. (2009) find that the MER from their proposed relationship and the actual MER can differ by a factor of upto 3.5 for an eruption plume height of about $6 \mathrm{~km}$, so the differences between the MER predicted by the different relationships are insignificant.

The effective source strength for fine ash is assumed to be,

$M_{\mathrm{f}}=\alpha_{\mathrm{f}}(t) 140.8 H^{4.15}$

where $M_{\mathrm{f}}$ is the effective rate of emission of fine ash, $\alpha_{\mathrm{f}}$ is the fine ash fraction, i.e. the fraction of ash which does not fall out close to the volcano. In principle the fine ash fraction is a function of the age of the ash, $t$, due to the effects of processes that are not represented in NAME, such as aggregation. However, these processes are expected to have their main effects for travel times less than $24 \mathrm{~h}$ (Rose et al., 2000). The fine ash fraction, $\alpha_{\mathrm{f}}$ will be estimated by comparing ash concentrations from NAME, using Eq. (1), with those obtained from the lidar.

Figure 1 shows a reconstruction of the time varying eruption plume heights (above mean sea level) which is similar to that in Webster et al. (2012). This reconstruction is based on the advice from the Icelandic Meteorological Office passed to the London VAAC during the eruption. It aims to broadly follow the upper estimates of the eruption height which were available at the time, while only responding to significant changes in activity. Also shown is the data from the Keflavík radar, published by Arason et al. (2011). The most noticeable difference between the two timeseries is that the reconstruction does not follow the short period variations seen in the radar data. During the period of interest (4-17 May) the reconstruction is a reasonable representation of the height of the eruption plume from the radar data. In calculating the MER using the heights in Fig. 1 no account has been taken of the effect that the ambient wind can have on the height of the eruption plume (Bursik, 2001).

To investigate the sensitivity of the model results to the assumed emission profiles simulations were performed using two different profiles. For the first set of simulations the emission of ash was assumed to be uniform between the top of the volcano and the top of the eruption plume, this is referred to as the uniform emission profile. For the second profile the emission of ash is assumed to be concentrated at the top of the eruption plume and is referred to as the top emission profile. In the top emission profile ash is emitted uniformly over a depth of $1000 \mathrm{~m}$, with the top of the layer of ash emissions corresponding to the height of the eruption plume. For both emission profiles the total erupted mass is given by Eq. 1.

\section{Lidar}

The lidar on the FAAM aircraft was a model ALS450 manufactured by Leosphere. It is an elastic backscatter lidar with an operating wavelength of $354.7 \mathrm{~nm}$. The instrument is mounted on the aircraft with a nadir view, with full overlap between the emitted beam and the receiver field of view occurring about $300 \mathrm{~m}$ below the aircraft (Marenco et al., 2011). For the cruise altitude of $8000 \mathrm{~m}$ the ash features that 
can be identified from the aircraft are restricted to heights below about $7700 \mathrm{~m}$.

Ash features were identified subjectively using lidar backscatter and depolarisation ratio plots. Ash was identified as having a high backscatter with a high depolarisation ratio, indicating irregular particles. Smaller aerosols (e.g. sulphate) tend to assume a spherical shape producing high backscatter and low depolarisation ratios (see Marenco et al. (2011) for details on the interpretation of the lidar returns).

Quantitative estimates of ash concentrations in the 0.6 to $35 \mu \mathrm{m}$ (volume equivalent) size range were obtained from the extinction coefficients derived from the lidar, after accounting for the extinction fraction in this size range and specific extinction derived from particle size distributions from in-situ measurements (Johnson et al., 2011; Marenco et al., 2011). The uncertainty in the concentrations is estimated to be a factor of 2 .

In many cases the profiles of the ash concentration derived from the lidar show considerable scatter in the vertical. To estimate column integrated mass loadings smooth profiles have been fitted by eye to the profiles of ash concentration obtained over horizontal distances of approximately $15 \mathrm{~km}$. In general the concentration profiles are approximately Gaussian in shape, although in many cases the profiles are slightly asymmetric about the maximum. To allow for this asymmetry Gaussian curves with different widths were fitted separately to the upper and lower parts of the lidar profiles. Where there were multiple layers Gaussian curves were fitted to each layer. The use of Gaussian curves is ultimately for convenience, and it provides quantitative measures for maximum concentrations and widths. However, it should be borne in mind that the fits to the data are not objective and hence no formal error estimates are available.

On 14 May, there is evidence that there were ice particles in the ash layers (Marenco et al., 2011). Obvious occurrences of cirrus forming in the ash cloud were removed from the dataset. However, it is possible that ice nucleated ash was present in the ash cloud, which would lead to ash concentrations being overestimated. The presence of ice was not a problem on the other days.

Typically the extent of the ash layers used in this study correspond to distances of $250-600 \mathrm{~km}$ and flight times of between $30 \mathrm{~min}$ and $1 \mathrm{~h}$. The ash concentrations from NAME are obtained over one hour, which provides statistical reliability. In comparing the lidar results to NAME the time taken to overfly the ash layers has been ignored and the output from NAME closest to the central time is used for the comparison. Over a period of an hour the evolution of the ash clouds simulated by NAME is relatively small and fixing the time in this way does not have a significant effect on the comparisons. In addition the use of NAME fields at a particular time to identify features that correspond to the observed ash layers allows location errors in the simulated clouds to be assessed.

\section{Results}

\subsection{Ash layer properties from lidar}

The average heights of the ash features identified from the FAAM lidar are plotted in Fig. 1, where they can be compared with the estimates of the eruption plume height. Because of the travel time (listed in Table 1 as ash age) the heights of observed features and the plume heights at the same time will not correspond, but it might be expected that the observed height will be related to the height of the eruption plume during the previous 1-3 days. There appears to be a tendency for the heights of the ash features observed by the lidar to be up to $1 \mathrm{~km}$ lower than the estimated height of the eruption plume used in NAME. The tendency for lidar ash features to be at a lower height than the height of the eruption plume estimated by the radar may be a result of fluctuations in plume height (Dacre et al., 2011; Folch et al., 2011), vertical transport in the atmosphere, overshooting and subsequent fall back of the plume, errors in the assumed heights or sedimentation of particles. Since the height of the eruption plume used in NAME aims to broadly follow the upper estimates of the eruption heights, it is likely to be greater than the mean height of the eruption plume which may be more representative of the height of the ash layers.

Figure 2 shows examples of the concentration profiles derived from the FAAM lidar on the 17 May together with the smooth profiles fitted to the data by eye. The aircraft track was approximately west to east along $54^{\circ} \mathrm{N}$. Although the individual estimates of concentration from the lidar show considerable scatter over a $15 \mathrm{~km}$ section the Gaussian curves provide a reasonable approximation to the observed profiles. The maximum concentrations occur at heights between $4 \mathrm{~km}$ and $6 \mathrm{~km}$, with the peak concentrations varying between $225 \mu \mathrm{g} \mathrm{m}^{-3}$ to $800 \mu \mathrm{g} \mathrm{m}^{-3}$. Because the curves are fitted by eye there are no formal estimates of the uncertainty in the maximum concentration, but based on experience fitting the curves to the observations a reasonable estimate of the uncertainty is $25-50 \mu \mathrm{g} \mathrm{m}^{-3}$. At the western end of the aircraft track (Fig. 2a) there is only one ash layer present while at the eastern end (Fig. 2c and d) the lidar shows multiple layers.

The Cloud Aerosol Probe (CAS) on the Bae 146 measured a concentration of $400-500 \mathrm{\mu g} \mathrm{m}^{-3}$ in a layer extending from $3.5-6.5 \mathrm{~km}$ at 14:45 UTC on 17 May (Turnbull et al, 2012). The in-situ observations do not appear to show the multiple layered structure at the most easterly profile in Fig. 2 which is in a similar location. The DLR Falcon also sampled the ash cloud on this day around $53^{\circ} \mathrm{N} 2^{\circ}$ E between 16:00-17:00 UTC, i.e. about $1.5 \mathrm{~h}$ after the profile shown in Fig. $2 \mathrm{~d}$ was obtained. The Falcon data show the ash layer to be between $3.5 \mathrm{~km}$ and $6 \mathrm{~km}$, with the maximum ash concentrations between $300-400 \mu \mathrm{g} \mathrm{m}^{-3}$, comparable to the FAAM lidar estimates (Schumann et al., 2011).

The standard deviations of the Gaussian sections that have been fitted to the lidar concentration profiles are typically 
Table 1. Estimates of distal fine ash fraction, $\alpha_{f}(\%)$.

\begin{tabular}{ccccc}
\hline $\begin{array}{c}\text { Date } \\
\text { May }\end{array}$ & $\begin{array}{c}\text { Uniform Source } \\
\alpha_{\mathrm{f}} \text { from CIML }\end{array}$ & $\begin{array}{c}\text { Top Source } \\
\alpha_{\mathrm{f}} \text { from CIML }\end{array}$ & $\begin{array}{c}\text { Top Source } \\
\alpha_{\mathrm{f}} \text { from } \mathrm{C}_{\max }^{\mathrm{b}}\end{array}$ & $\begin{array}{c}\text { Ash Layer } \\
\text { Age (h) }\end{array}$ \\
\hline 4 & 10.0 & 3.5 & 8.0 & 25 \\
$5(L)^{\mathrm{c}}$ & 11.2 & - & - & 37 \\
$5(U)^{\mathrm{c}}$ & 4.1 & 2.4 & 3.5 & 27 \\
14 & 18.5 & 5.2 & 12.9 & 33 \\
16 & 0.9 & 1.8 & 3.7 & 55 \\
17 & 2.7 & 1.2 & 3.0 & 77 \\
\hline
\end{tabular}

${ }^{a}$ Column Integrated Mass Loading

${ }^{b}$ Maximum Concentration

$\mathrm{c}(\mathrm{U})$ is for the upper layer $(\mathrm{L})$ is for the lower layer
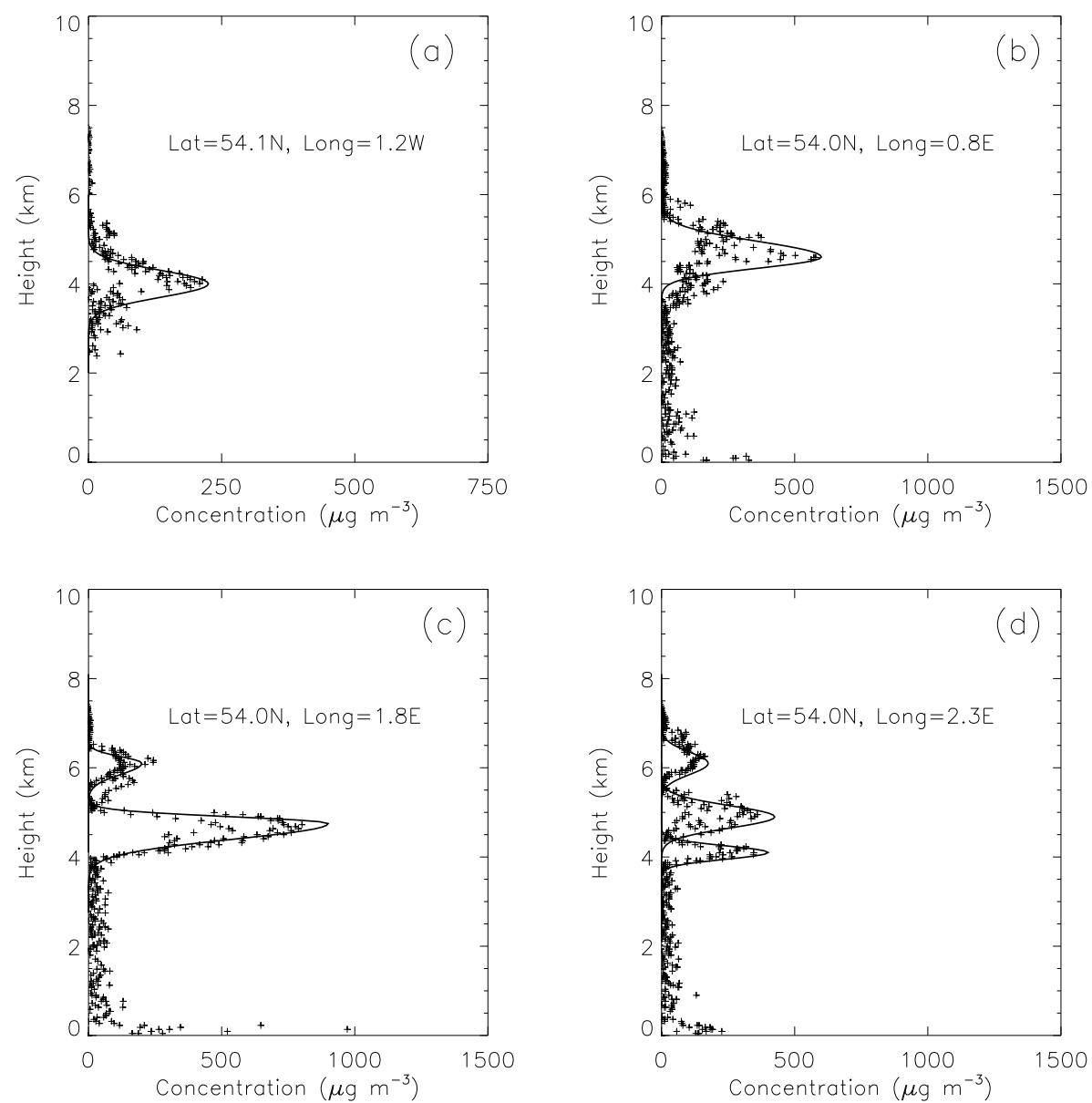

Fig. 2. Examples of concentration profiles derived from lidar between 14:00 and 15:00 UTC on the 17 May. The crosses show the concentration estimates from the lidar, the solid curves show the Gaussian curves that have been fitted to the observations by eye.

about $300 \mathrm{~m}$. However, to make comparisons with the NAME simulations it is useful to have a simple measure of the thickness of an ash layer which does not depend on the detailed shape of the concentration profile. The ratio of the integrated column mass to the maximum concentration will be used as

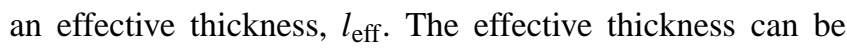
interpreted as the thickness of a layer with a constant con- centration equal to the observed maximum that gives the observed column integrated mass. For a Gaussian profile with standard deviation $\sigma, l_{\mathrm{eff}}=\sqrt{2 \pi} \sigma$.

Figure 3 shows the maximum concentrations obtained from the lidar as a function of the column integrated mass, estimated from the Gaussian profiles. The multiple layers seen in some of the profiles on the 17 May have been treated 


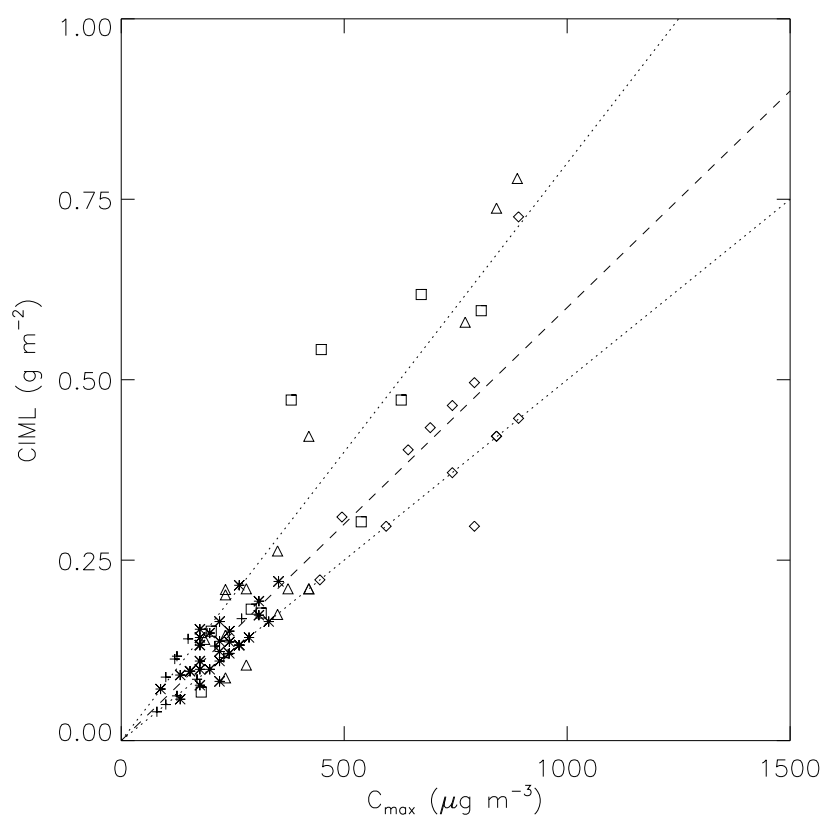

Fig. 3. Comparison between the column integrated mass load (CIML) and the maximum concentration $\left(C_{\max }\right)$ for lidar observations. The dashed line corresponds to an effective depth for the ash layers of $600 \mathrm{~m}$, the dotted lines are for effective depths of $500 \mathrm{~m}$ and $800 \mathrm{~m}$. The symbols show results for different flights. 4 (crosses); 5 May (stars); 14 May (diamonds); 16 May (triangles) and 17 May (squares).

as a single layer. The effective depth of the ash layers detected by the lidar is generally between $500 \mathrm{~m}-800 \mathrm{~m}$ which is about $10-20 \%$ of the rise height of the eruption plume. The thickness of the ash layers observed by the lidar are comparable to thicknesses estimated by Scollo et al. (2010) using data from MISR (Multi-angle Imaging SpectroRadiometer) for the 2001 and 2002 eruptions of Etna. The Scollo et al. (2010) results were obtained within $250 \mathrm{~km}$ of Etna. Carey and Sparks (1986) suggest that close to the eruption the thickness of the umbrella region of the ash cloud is $\approx 0.3 \mathrm{H}$. This suggests that what appear as relatively thin ash layers observed by the lidar probably reflect the depth of the near source eruption plume. If this is the case then it suggests that vertical turbulent diffusion within the troposphere was not important during transport (or was partly balanced by thinning of the layers due to shear).

\subsection{Simulated ash clouds: horizontal structure}

Figure $4 \mathrm{a}-\mathrm{j}$ shows contour plots of the column integrated mass loadings (CIML) obtained from NAME for each of the flights. Figure 4a, c, e, g, i shows the results obtained with a uniform emission profile and Fig. 4b, d, f, h, j shows results for the top emission profile. The locations of the ash features detected by the FAAM lidar are marked by the line segments.
On the 4, 5 and 14 May the locations of the areas of highest ash concentrations in the NAME simulations are not particularly sensitive to the assumptions about the ash emission profile, although the actual concentrations do depend on the emission profile. This is particularly evident on the 14 May (Fig. 4e and f) when the maximum concentrations over western Scotland and northwest England are higher for the top emission profile than for the uniform emission profile. The extent of the areas of low ash concentration on these days are more sensitive to the emission profile, being less extensive for the top emission profile. The flights on the 4 and 5 May took place in areas of low ash concentration in the NAME simulations, so quantitative comparison with the lidar data on these days is likely to be sensitive to the assumed emission profiles.

The areas of high ash concentration in the NAME simulations on the 16 and 17 May are more sensitive to the form of the emission profile than on the other days studied. On both days the western boundary of the high concentration ash is further to the east in the simulations that use the top emission profile compared to the simulations that used the uniform emission profile. The boundary of the simulated ash cloud over Ireland on the 16 May using the top emission profile is consistent with the observations of Rauthe-Schoch et al. (2012). On both the 16 and 17 May the aircraft flew in the areas in which both sets of NAME simulations indicate relatively high ash concentrations.

\subsection{Simulated ash clouds: vertical structure}

Vertical cross sections of the simulated ash layers are shown in Figs. $5 \mathrm{a}-\mathrm{c}, 7 \mathrm{a}-\mathrm{c}$ and $8 \mathrm{a}-\mathrm{c}$ with the layers observed by the FAAM lidar being marked for comparison. With the exception of the 4 May the cross sections are taken along the aircraft flight tracks, which were approximated by a series of line segments The ash concentrations from NAME were interpolated onto the flight tracks at points separated by $10 \mathrm{~km}$. For the 14, 16 and 17 May the cross sections are almost along straight lines orientated predominantly north-south or eastwest. For these flights it is convenient to use latitude or longitude as the horizontal co-ordinate in the plots, although the cross sections are taken along the aircraft track. On the 4 and 5 May the aircraft heading varies while flying over the ash cloud and for these cross sections the horizontal co-ordinate is distance from a point on the flight track before the ash was encountered. Distances are taken along the aircraft flight track from this point.

A general feature of the cross sections through the simulated ash clouds is that they show layering, either single layers on the 4, 14 and 17 May (Fig. 7) or multiple layers on the 5 and 16 May (Figs. 5a and b and $8 b$ ). The presence of layers in the simulations does not appear to depend on the details of the emission profile, with layers present in both sets of simulations. The simulated ash layers appear to 

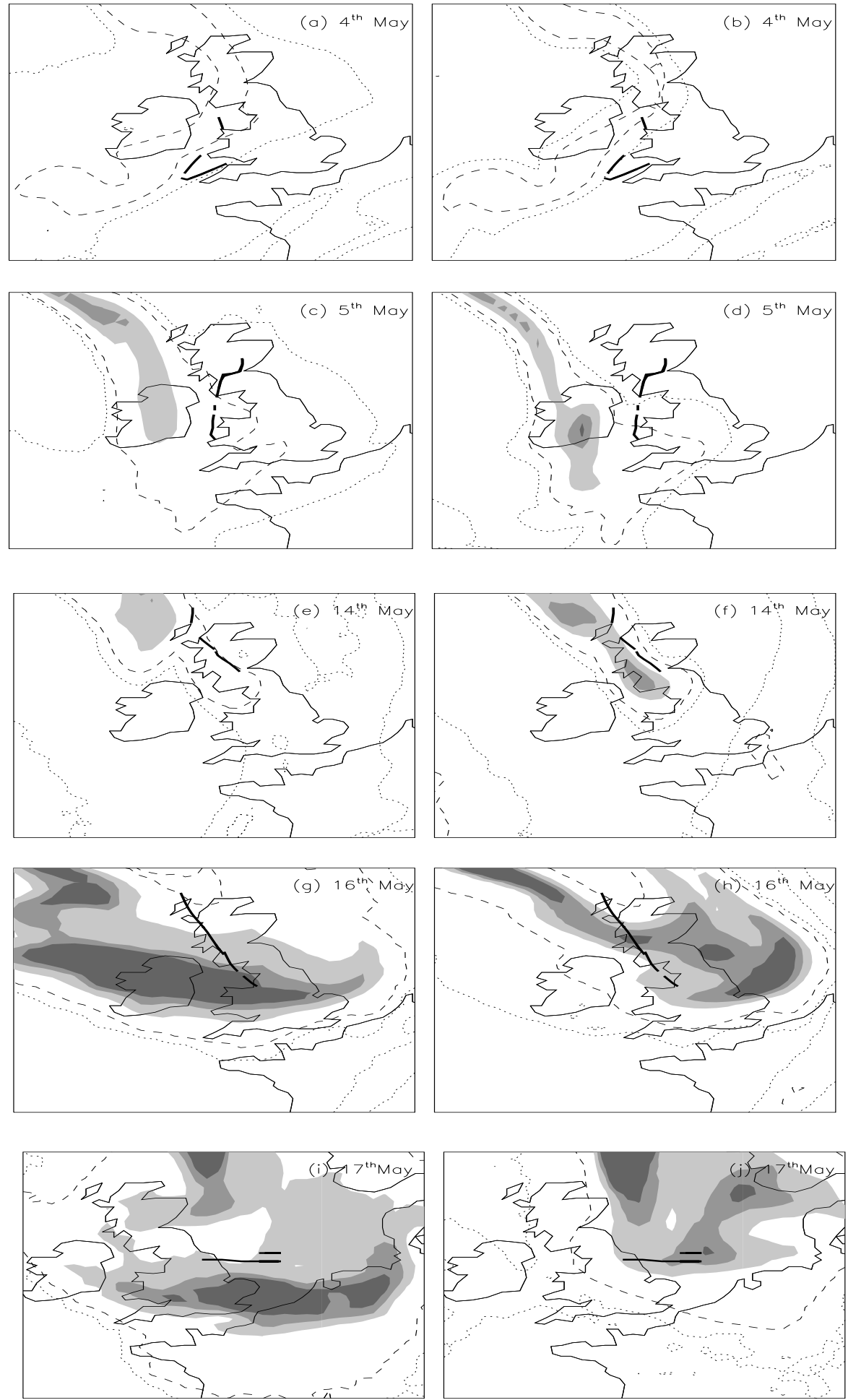

Fig. 4. Maps showing the column integrated mass loadings simulated by NAME. The figures on the left show simulations where the emission profiles is uniform between the top of the volcano and the top of the eruption plume, figures on the right are for an emission profile concentrated at the top of the eruption plume. The dotted contour corresponds to a column integrated mass loading of $0.02 \mathrm{~g} \mathrm{~m}^{-2}$ and the dashed contour $0.2 \mathrm{~g} \mathrm{~m}^{-2}$. The filled contours show 10,20 and $30 \mathrm{~g} \mathrm{~m}^{-2}$ (note these concentrations do not account for fall out of ash near the volcano). The thick black lines mark the locations of the ash features analysed in the text. 

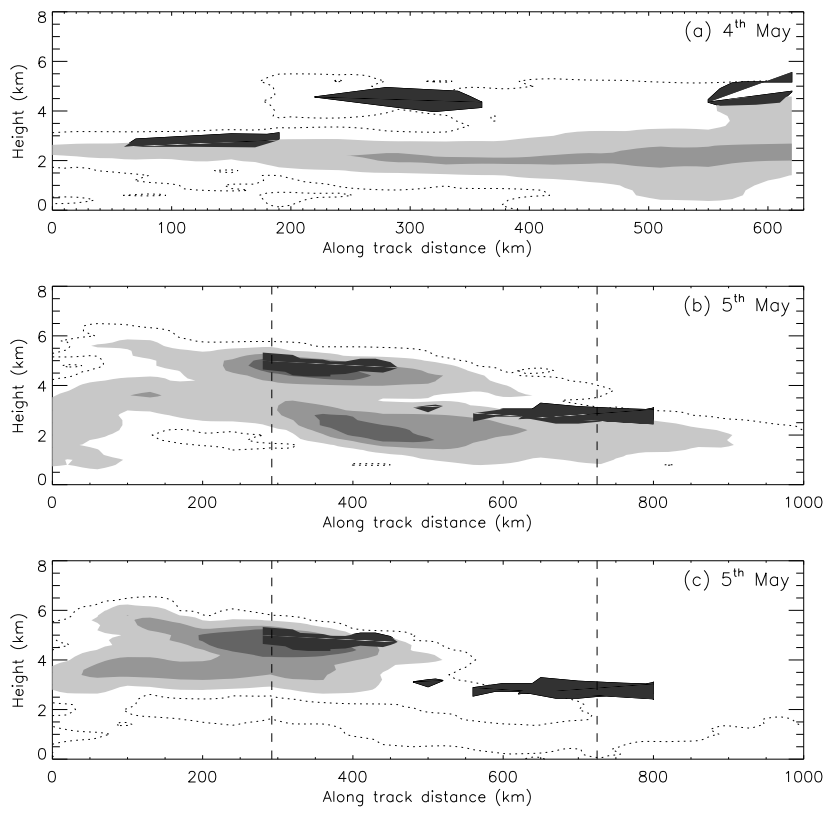

Fig. 5. Cross sections of ash concentration taken along aircraft tracks from NAME simulations for the 4 and 5 May. (a) 4 May, uniform emission profile (b) 5 May, uniform emission profile and (c) 5 May, emissions at top of plume. The dark grey shaded areas show the outlines of ash features identified by the lidar. The dotted contour corresponds to a concentration of $2 \mu \mathrm{g} \mathrm{m}^{-3}$ and is taken to show the edge of the ash cloud. The filled contours correspond to 20,200 , and $200 \mu \mathrm{g} \mathrm{m}^{-3}$ (note these concentrations do not account for fall out of ash near the volcano).

correspond reasonably well to observed ash layers, although they are generally thicker.

On the 4 and 5 May the lidar detected ash layers at heights of around $3 \mathrm{~km}$ and $5 \mathrm{~km}$. The NAME simulations using a uniform emission profile also indicates the presence of ash at both heights, although with almost zero concentration on the 4 May. The lower ash layer observed on the 5 May lies towards the edge of the NAME ash cloud, but higher concentrations in the NAME cloud are present about $200 \mathrm{~km}$ to the south. With the top emission profile the NAME simulations on the 4 (plot not shown) and 5 May do not show ash layers around $3 \mathrm{~km}$, but the layer around $5 \mathrm{~km}$ on the 5 May still corresponds to a layer that is present in the NAME simulation.

Figure $4 \mathrm{a}$ and $\mathrm{b}$ show the aircraft track on the 4 May to be close to the edge of the simulated ash cloud, particularly with the top emission profile. The relationship between the aircraft observations and model results on the 4 May is illustrated more clearly by an east-west cross section through the model ash cloud. The cross sections shown in Fig. 6a and $\mathrm{b}$ are taken along $52^{\circ} \mathrm{N}$. Note that the upper and lower ash features observed by the lidar occur at different latitudes.

The observed ash patches are towards the eastern edge of the NAME ash cloud. Thomas and Prata (2011) show sulphur dioxide retrievals for this day which suggest that the
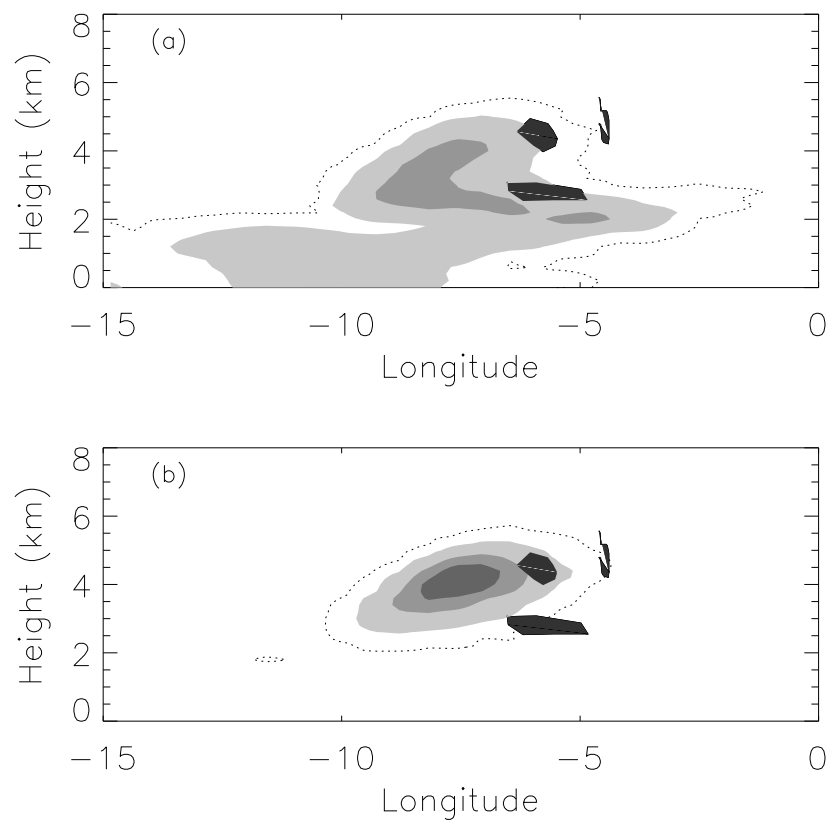

Fig. 6. East-West cross sections of ash concentration on 4 May along $52^{\circ} \mathrm{N}$ (a) Uniform emission profile. (b) Top emission profile. Other details as Fig. 5

ash cloud may be further east than NAME indicates. Such an error would make the association between the NAME ash clouds and the observed features closer. Because of its thickness the NAME ash cloud obtained with the top emission source could also be considered to be associated with the observed ash patches. More information on the actual ash distribution is needed to provide a more precise interpretation of the relationship between the observed ash features and the results from NAME.

On the 14, 16 and 17 May (Figs. 7 and 8) the details of the vertical structure of the simulated ash clouds depend on the ash emission profile. On the 14 May the concentrations in the simulated layer are higher using the top emission profile, compared to those obtained using a uniform emission profile. On the 17 the western extent of the ash cloud appears to be better simulated using the top emission profile (compare Figs. $7 \mathrm{c}$ and $8 \mathrm{c}$ ).

On the 16 May both of the NAME simulations show a layer that appears to correspond to the observed ash layer but which, in both simulations, is too far south. Schumann et al. (2011) comment that the London VAAC forecasts on this day showed the ash to be further south than observed by the DLR Falcon or SEVIRI. It is interesting that the same error appears in the present simulations which use analysed wind fields. This location error is probably caused by the cumulative effect of errors in the driving meteorology en route, similar to those found for the earlier period of the eruption in Dacre et al. (2011) or to a timing error in the emissions. To allow quantitative comparison of NAME with the lidar in 

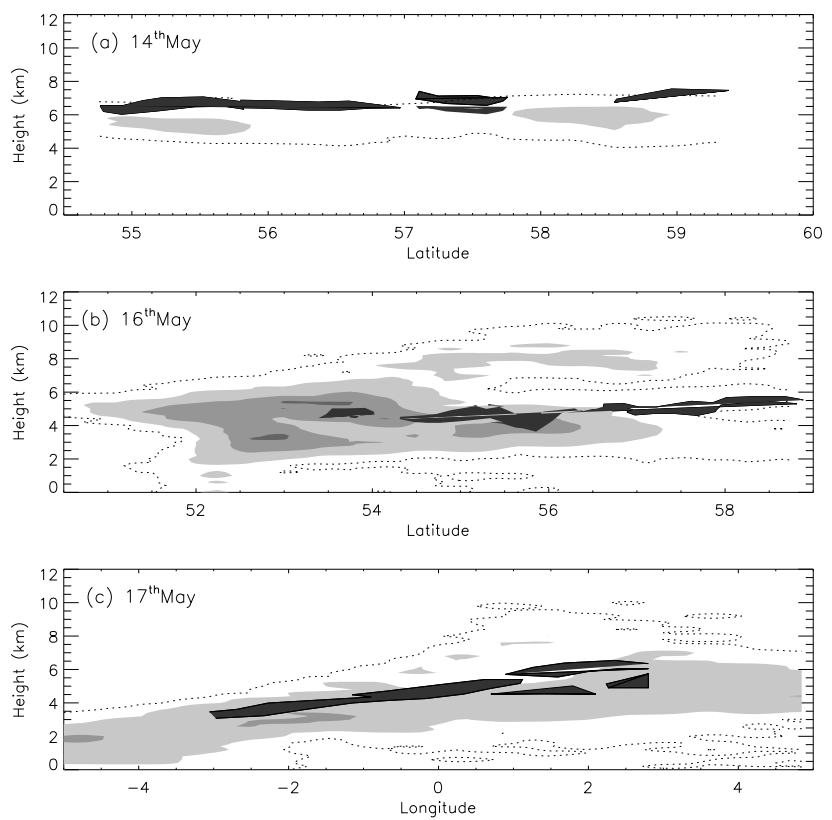

Fig. 7. Cross sections of ash concentration taken along aircraft tracks for simulations with a uniform emission profile. (a) 14 May, (b) 16 May and (c) 17 May. Other details as Fig. 5.

this case the position of the simulated ash cloud is moved in the direction of the aircraft track so the southern edges of the simulated and observed ash layers match.

\subsection{Quantitative comparison between lidar and NAME}

The correspondence between the observed ash layers and the ash layers in the NAME simulations suggests that quantitative comparisons between NAME and the lidar can be made for the individual layers. Since the ash layer thicknesses differ the column integrated mass loadings are compared since they are not sensitive to the details of the vertical structure. Figure 9 show the CIMLs obtained from NAME along the cross sections in Figs. 5, 6, 7 and 8 compared to those estimated from the lidar. For the 4 May the comparison between NAME and the lidar observations is done using the cross sections in Fig. 6a and $\mathrm{b}$ rather than using the along track profiles. The distal fine ash fraction defined in Eq. (2) has been estimated by scaling the mass loadings obtained from NAME to match the lidar estimates. The values of $\alpha_{\mathrm{f}}$ obtained from both sets of NAME simulations are listed in Table 1.

The spatial variation of the observed column loadings and those from NAME are generally in good agreement, although there are differences. Figure 9a shows the comparisons for the 4 May along an east-west cross sections in Fig. 6. There is agreement between the variations in the observed ash mass and that derived from NAME for the $3 \mathrm{~km}$ feature. For the top emission profile there is reasonable agreement between the observations and NAME if it is assumed that the NAME ash cloud is about $1.5^{\circ}$ too far to the west. Such an error
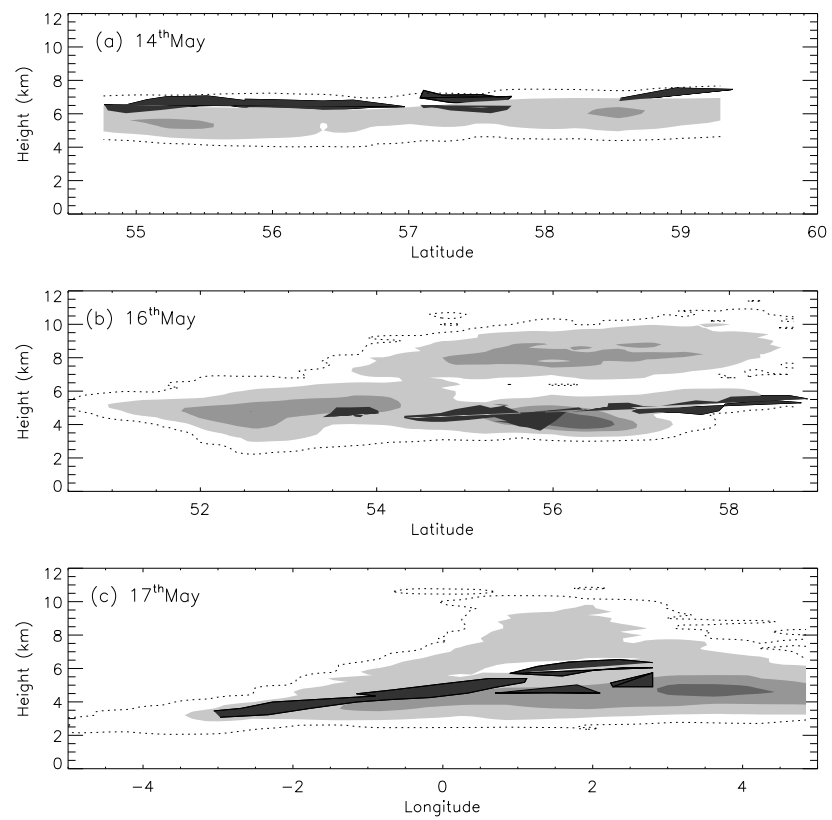

Fig. 8. Cross sections of ash concentration taken along aircraft tracks for simulations with emissions concentrated at the top of the eruption plume. (a) 14 May, (b) 16 May and (c) 17 May. Other details as Fig. 5.

would agree with the satellite observations in Thomas and Prata (2011).

For the 5 May Fig. $9 \mathrm{~b}$ suggests that the ash layer at $3 \mathrm{~km}$ is much less extensive than the simulated ash cloud using the uniform source. In particular the maximum in the column integrated mass around $400 \mathrm{~km}$ in the simulated ash cloud does not appear to correspond to any feature seen by the lidar. However, using a top source in NAME, the ash layer at $3 \mathrm{~km}$ is missing entirely in the simulation showing that some ash must be emitted below $3.5 \mathrm{~km}$ for the $3 \mathrm{~km}$ ash layer to be simulated in NAME.

The short horizontal line in Fig. 9d marks a region where the observed ash layer becomes very thin and the column loading of ash is negligible. (Note that the ash layer simulated by NAME has been moved $3^{\circ} \mathrm{N}$ in order to perform the quantitative comparison). The results from NAME do not show this gap, but vary more smoothly. The smooth spatial variation of simulated ash layers is due to the resolution of the meteorological model $(25 \mathrm{~km})$, the smooth temporal variation of the meteorological fields (updated every $3 \mathrm{~h}$ ), the lack of rapid fluctuations in the source (in both the vertical, and in time) and the parameterisation of sub-gridscale processes. The NAME simulations appear to capture variations on scales of $100-200 \mathrm{~km}$.

Of all of the simulations the spatial variation in the column mass loadings from NAME appear to be the most sensitive to the assumed emission profile on the 17 May (Fig. 9c). The simulation which uses the top emission profile shows 

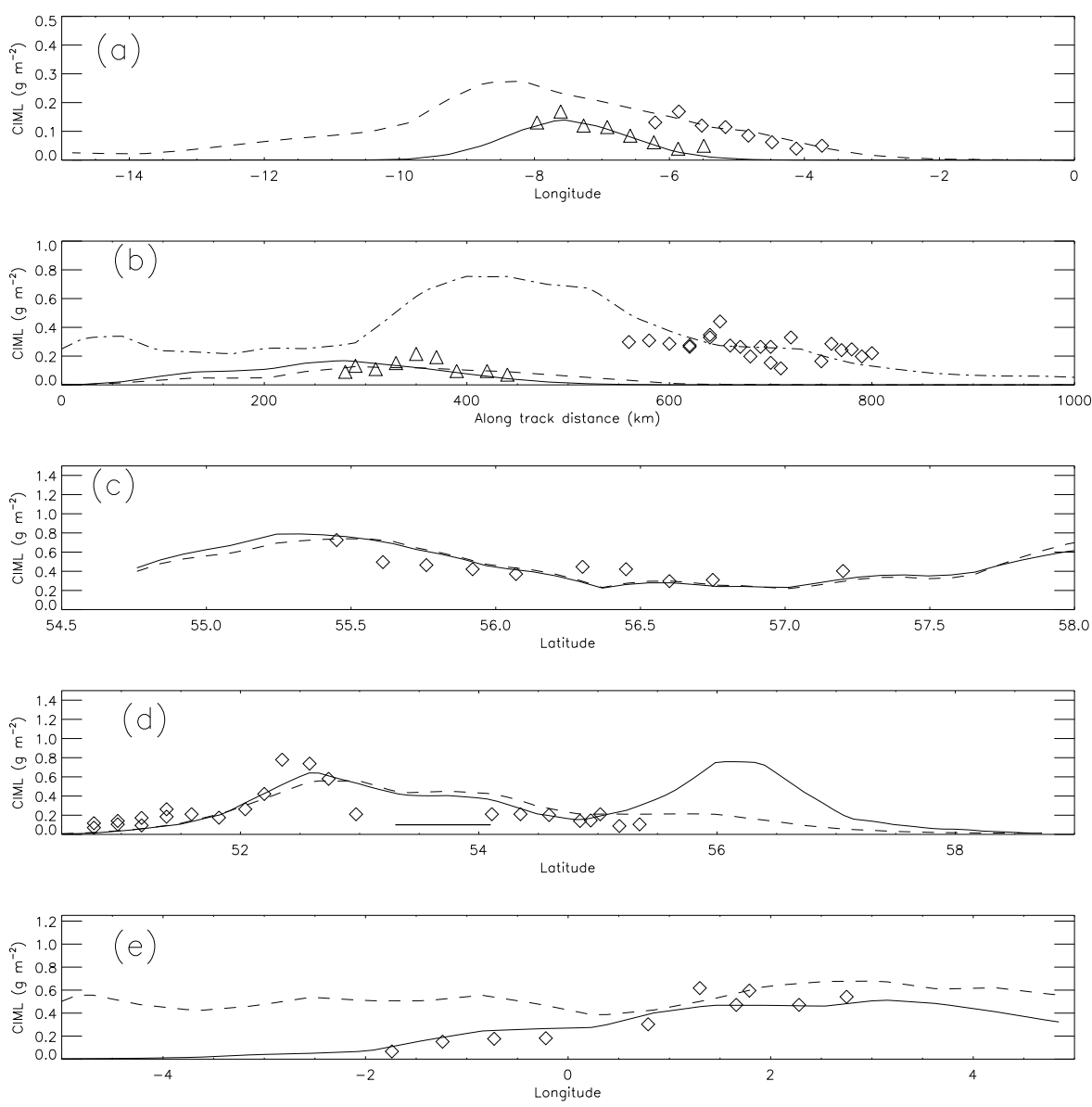

Fig. 9. Comparisons between lidar estimates of CIML and estimates from NAME. (a) Estimates of the CIML from the lidar on 4 May (diamonds) and offset by $1.5^{\circ} \mathrm{W}$ (triangles). Estimates of the CIML from NAME, top source (full curve) and uniform emissions (dashed curve). (b) Estimates of the CIML for the $3 \mathrm{~km}$ layer on the 5 May (diamonds) and the $5 \mathrm{~km}$ layer (triangles). Estimates of the CIML from NAME using uniform emissions for the ash layer at $3 \mathrm{~km}$ (dot-dashed line), for the layer at $5 \mathrm{~km}$ for top source (solid line), for the uniform emissions (dashed line). The NAME results are scaled to fit the observations. (c) Lidar estimates of the CIML on the 14 (diamonds). Estimates of the CIML from NAME for top source (solid line) and uniform emissions (dashed line). (d) as (c) but for 16 May. (e) as (c) but for 17 May.

good agreement with the lidar estimates, with both the lidar and NAME column loadings being small to the west of $2^{\circ} \mathrm{W}$. With the uniform emission profile the column loadings in the NAME simulation extend much further west than observed. However, both simulations give a similar value for $\alpha_{\mathrm{f}}$ using the observed column loadings at the eastern end of the aircraft track.

Most of the values for $\alpha_{\mathrm{f}}$ from the comparison of the CIMLs which are listed in Table 1 are less than about $5 \%$, the two exceptions being $\alpha_{\mathrm{f}}$ for the lower layer on the 5 May and on the 14 May for the simulation using the uniform emission profile, which are, respectively, $11 \%$ and $18 \%$. Using the top emission profile the value of $\alpha_{\mathrm{f}}$ for the 14 May is reduced by a factor of three to $\sim 5 \%$. This large change in $\alpha_{\mathrm{f}}$ is due to the increased concentrations that occur in the layer above $5 \mathrm{~km}$ over Scotland and north west England, when the top emission profile is used compared to the uniform emis- sion profile. With the uniform source ash below $5 \mathrm{~km}$ appears to be transported to the north east, away from the UK.

Figure 10 compares the lidar and NAME estimates of the column integrated mass taken from the simulations using the uniform emission profile for May 5 and the top emission profile for 14, 16 and 17 May. A reasonable estimate of the distal fine ash fraction is $2.8 \%$, with of order a factor of two variation encompassing the results from most of the days. These estimates of $\alpha_{\mathrm{f}}$ are in reasonable agreement with those obtained from ground-based lidar and NAME during the initial phase of the eruption in April (Dacre et al., 2011; Devenish et al., 2011).

There are some observational estimates from previous volcanic eruptions of the fraction of the erupted mass that survives the initial fall out phase which can be compared with the present results. Wen and Rose (1994) used AVHRR (Advanced Very High Resolution Radiometer) data to estimate the mass of ash in the $13 \mathrm{hr}$ old ash cloud from August 


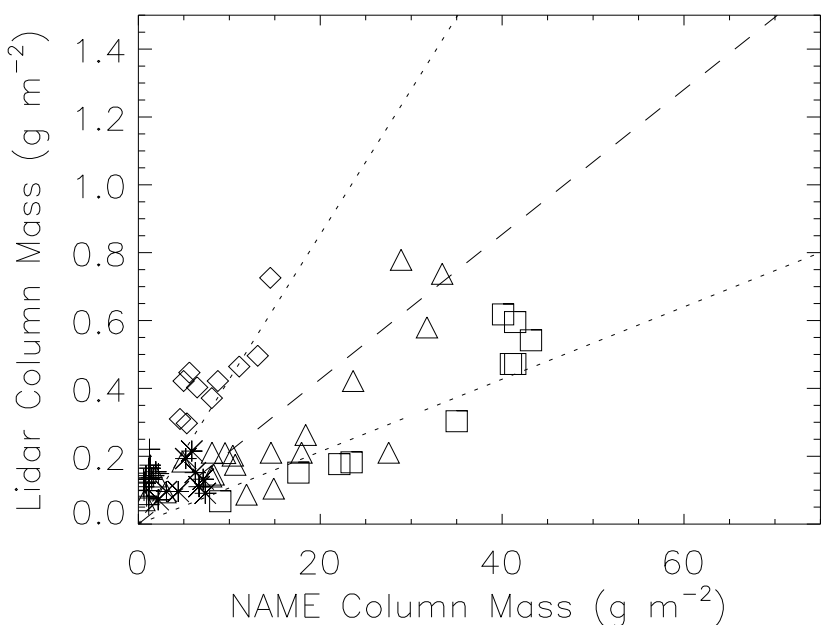

Fig. 10. Comparison between the CIMLs from NAME simulations and estimates from the FAAM lidar. The symbols are; $3 \mathrm{~km}$ layer 5 May (crosses); $5 \mathrm{~km}$ layer 5 May (stars); 14 May (diamonds); 16 May (triangles) and 17 May (squares). The dashed line shows $y=0.028 x$, the dotted lines have gradients of twice and half that of the dashed line.

1992 eruption of Spurr volcano. The ash cloud contained $0.7-0.9 \%$ of the mass deposited at the surface. Rose et al. (2000) list a number of estimates of the fine ash fraction derived from satellite observations of the ash clouds for a number of eruptions. For the three eruptions of Spurr in 1992 the fraction of ash remaining suspended in the atmosphere after $24 \mathrm{~h}$ was $0.7-2.6 \%$. Bearing in mind that the values of $\alpha_{\mathrm{f}}$ obtained in this study are based on estimates of the erupted mass calculated from Eq. 1 they are consistent with the more direct estimates.

\subsection{Maximum concentrations}

In general the observed ash layers are thinner than the corresponding layers simulated by NAME. This does not affect the comparison of the integrated column masses, assuming that the effects of vertical wind shear on the ash cloud are small. However, in general the maximum concentrations simulated by NAME, when scaled using $\alpha_{\mathrm{f}}$, will underestimate actual maximum concentrations. This is illustrated in Fig. 11 which shows examples of the profiles of ash concentration from the lidar and the corresponding profiles simulated by NAME, scaled by the distal fine ash fraction determined from the integrated column mass. The greater depth of the simulated ash layers compared to the observed depth is clear as are the lower maximum concentrations.

The peak concentrations from the lidar and from the corresponding layers in the NAME simulations using the top emission profile are compared in Fig. 12. There is a reasonable correlation between the lidar and NAME for individual flights, which is similar to that found for the column mass loads (see Fig. 10). These correlations suggest that the iden- tification of the observed ash layers with ash layers in the NAME simulations is justified. The ratios of lidar to NAME maximum concentrations are also listed in Table 1. They are larger than the corresponding ratios for the column integrated masses, consistent with the simulated layers being thicker than the observed ash layers (see Fig. 11). Comparison of the lidar and NAME estimates of the maximum concentration (Fig. 12) indicates that, with $\alpha_{\mathrm{f}}$ estimated from the column integrated mass loads, the maximum concentrations are underestimated by a factor of $\sim 2$.

\section{Discussion}

This study has investigated how well the NAME model predicted the structure of the ash clouds from the eruption of Eyjafjallajökull and the changes to the structure that occurred when the emission profiles were altered. Since it was not intended to produce the best simulations from NAME only simple emission profiles were considered.

For the 14, 16 and 17 May the ash features detected by the lidar could be readily associated with features in the NAME simulations, although there could be errors in the location of the simulated ash layers. Dacre et al. (2011) found timing errors of several hours in the predicted arrival of an ash layer over the southern UK at the start of the eruption in April. For these three days in May it was found that restricting the emission of ash to the upper part of the eruption plume gave the best comparison between NAME and the observations.

On the 4 and 5 May when the eruption intensity was low, although increasing, the situation is less clear. Arguably a uniform emission profile gives the best agreement between NAME and the observations. However, it is difficult for these days to accurately define the height of the eruption plume since it was frequently obscured from the radar at Keflavik (Arason et al., 2011). Dacre et al. (2011) and Devenish et al. (2011) show that short term variations in the height of the eruption plume can be detected in the ash cloud at long ranges. The use of the uniform emission profile may simply capture the effects of unresolved variations in the height of the eruption plume, even if the actual emission profile at any time has the ash source concentrated at the towards the top.

The mass eruption rate for the NAME simulations was estimated from the empirical relationship between the MER and the height of the eruption plume proposed by Mastin et al. (2009). This relationship does not consider the effects of atmospheric stratification or wind on the height that the eruption plume reaches. The effects of stratification were taken into account by Stohl et al. (2011) and Kristiansen et al (2012) by using a one dimensional model of the volcanic plume (Mastin , 2007) to estimate the apriori emissions. The comparison between NAME and the estimates of ash concentrations from the lidar gives a fine ash fraction of 2 $5 \%$, which is in agreement with previous estimates Rose et 

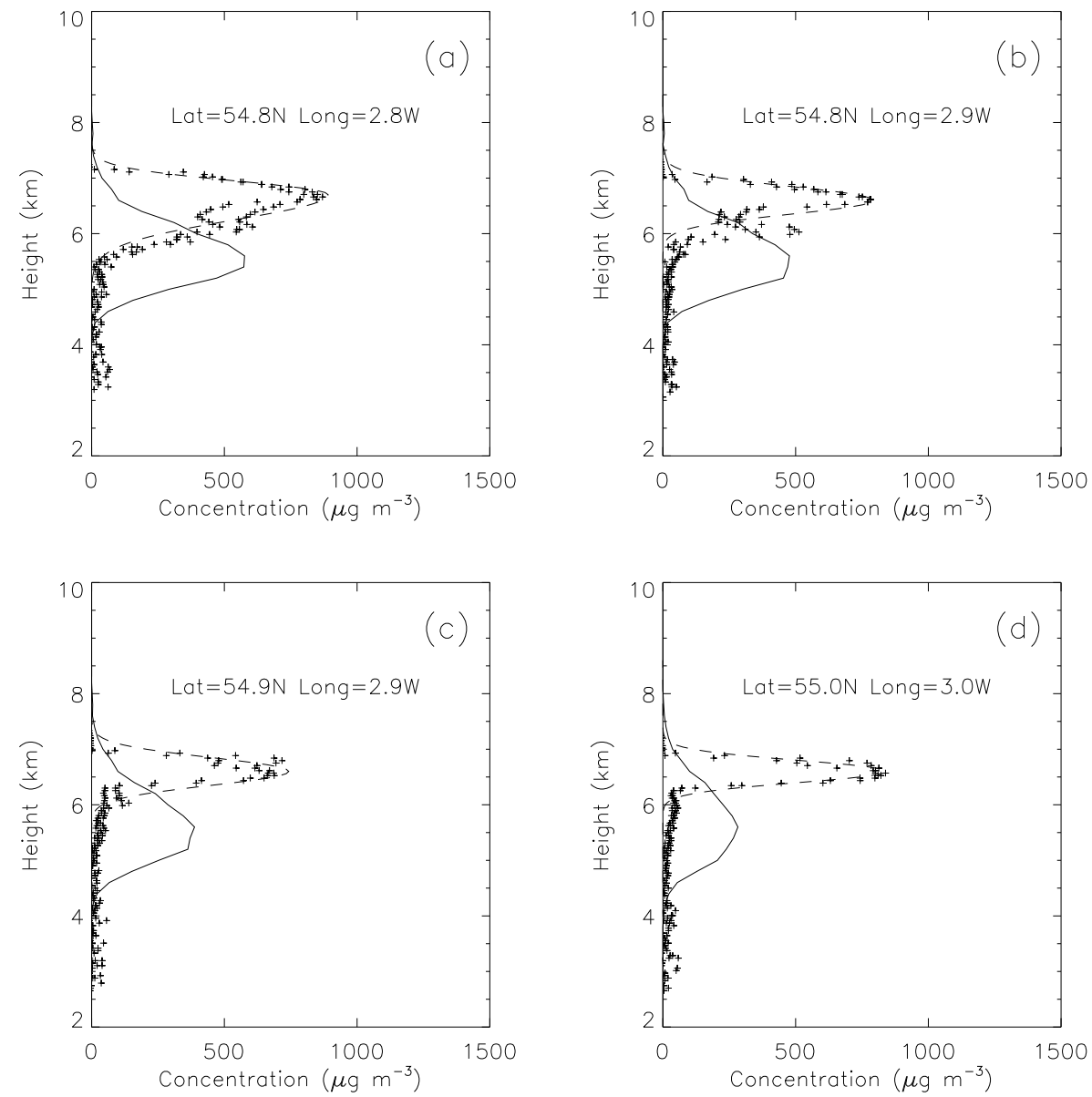

Fig. 11. Examples of concentration profiles, estimated from lidar extinction profiles on 14 May and simulated by NAME using the top emission profiles. The NAME profiles have been scaled by the distal fine ash fraction determined from the CIMLs. The small crosses are the estimates of concentration from the lidar extinction, the dashed curves show the fits to the lidar data and the solid curves are from NAME.

al. (2000) and the fine ash fraction estimated at the start of the eruption by Dacre et al. (2011).

The fine ash fraction derived in this study depends on the accuracy of the Mastin et al. (2009) relationship. The total mass of ash emitted into the atmosphere has been estimated to be $378 \pm 100 \mathrm{Tg}$ based on sampling of the tephra blanket in Iceland (Gudmundsson et al , 2012). Using the height reconstruction shown in Fig. 1 the mass erupted over the period of the eruption is $431 \mathrm{Tg}$, which is in reasonable agreement with the direct estimate. Stohl et al. (2011) and Kristiansen et al (2012) estimated the emissions of fine ash to be $\sim 8 \mathrm{Tg}$, which with the direct estimate of the total erupted mass implies a fine ash fraction of $\sim 2 \%$. This is in good agreement with the present estimate.

The ash clouds in NAME are significantly thicker than the observed ash layers, and this leads to a reduction in the maximum concentration relative to the mean concentration. The increase in the thickness of the simulated ash clouds appears to occur close to the source, effectively spreading the emissions over a greater depth than that specified. Devenish et al. (2011) show that for a period in April parametrizations intended to represent the effects of turbulence and meandering have a significant effect on the thickness of the simulated ash layers. The effective thickness of the emissions in the top emission profile is similar to that derived by Stohl et al. (2011) and Kristiansen et al (2012) using the inversion technique. However, it is not clear to what extent their results, at least for the emissions derived from the NAME model, are affected by errors in the vertical structure of the simulated ash clouds found here.

The uncertainties in the estimated fine ash fractions are large due to the large errors in the ash concentrations estimated from the lidar. The estimates of ash concentrations from the lidar are considered good to within a factor of two. This large error arises because of uncertainties in the parameters that are used to convert the extinction coefficients from the lidar to concentrations (Marenco et al., 2011). The error in the estimated emissions from the sampling of the tephra blanket is $25 \%$ (Gudmundsson et al , 2012) and 50\% for the total emissions inferred from the satellite retrievals (Stohl et 


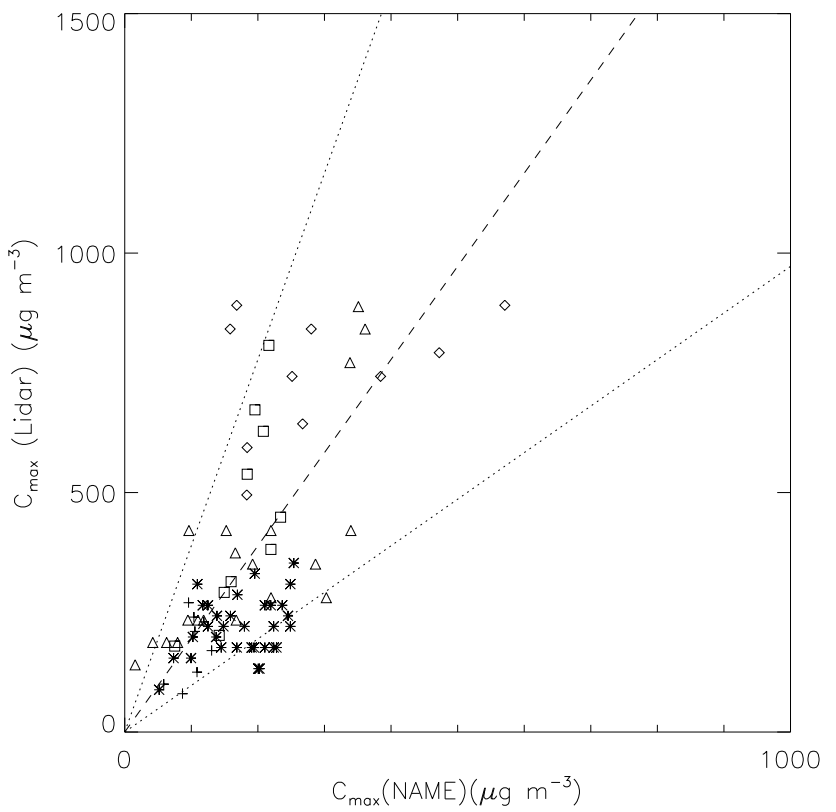

Fig. 12. Comparison between maximum concentrations from the NAME simulations and estimated from the FAAM lidar. The NAME concentrations have been scaled by the distal fine ash fraction determined from the CIML. The symbols are the same as Fig. 10. The dashed line shows $y=1.95 x$, the dotted lines have gradients that are twice and half those of the dashed line.

al., 2011; Kristiansen et al., 2012). Despite this the consistency of the results shows that using empirical relationships to estimate the emission source properties gives reasonable results, with the proviso that good observations of the height of the eruption plume are available.

\section{Conclusions}

Within the rather large uncertainties associated with the observations the study suggests the following conclusions.

- The horizontal structure of the simulated ash clouds compares reasonably with the structure from the aircraft observations. However, there may be errors of order $100 \mathrm{~km}$ in the position of simulated ash clouds.

- Generally having an elevated ash source gives the best simulated ash clouds if information on the height of the eruption plume is available.

- Empirical relationships between the mass eruption rate and height of the eruption plume provide reasonable estimates of concentrations when combined with an appropriate distal fine ash fraction.

- The comparisons suggest a distal fine ash fraction of 2-5\% for the Eyjafjallajökull eruption, similar to previ- ous estimates from other eruptions, and estimated from satellites for this eruption.

Overall this study shows that existing VATD models can be used to provide reasonable guidance on the structure and concentrations of ash in volcanic clouds to provide warnings to aviation in the event of an eruption.

Acknowledgements. The authors would like to thank Steve Sparks for helpful discussions on microphysical processes in volcanic clouds and for comments on the manuscript. We would also like to thank Helen Webster and Matthew Hort at the Met Office for useful feedback on the manuscript. Alan Grant was funded by a National Centre for Atmospheric Science (NCAS) national capability grant. Airborne data was obtained using the BAe-146-301 Atmospheric Research Aircraft (ARA) flown by Directflight Ltd and managed by the Facility for Airborne Atmospheric Measurements (FAAM), which is a joint entity of the Natural Environment Research Council (NERC) and the Met Office.

Edited by: G. Pappalardo

\section{References}

Arason, P., Petersen, G. N., and Bjornsson, H.: Observations of the altitude of the volcanic plume during the eruption of Eyjafjallajökull, April-May 2010, Earth Syst. Sci. Data, 3, 9-17, 2011, http://www.earth-syst-sci-data.net/3/9/2011/.

Ansmann, A.. Tesche, M., Gross, S., Freudenthaler, V., Seifert, P., Hiebsch, A., Schmidt, J., Wandinger, U., Mattis, I., Muller, D., and Wiegener, M.: The 16 April 2010 major volcanic ash plume over central Europe: EARLINET lidar and AERONET photometer observations at Leipzig and Munich Germany. Geophys. Res. Lett., 37, L13810, doi:10.1029/2010GL043809, 2010.

Bursik, M.: Effect of wind on the rise height of volcanic plumes, Geophys. Res. Lett., 18, 3621-3624, 2001.

Carey, S. and Sparks, S.: Quantitative models of the fallout and dispersal of tephra from volcanic eruption columns, Bull. Volc., 48 , 109-125, 1986.

Dacre, H. F., Grant, A. L. M., Hogan, R. J., Belcher, S. E., Thomson, D. J., Devenish, B., Marenco, F., Hort, M., Haywood, J. M., Ansmann, A., Mattis, I., and Clarisse, L.: Evaluating the structure and magnitude of the ash plume during the initial phase of the 2010 Eyjafjallajökull eruption using lidar observations and NAME simulations, J. Geophys. Res., 116, D00U03, doi:10.1029/2011JD015608, 2011.

Dacre, H. F., Grant, A. L. M., Thomson, D. J., and Johnson, B. T.: Observations and model simulations of column integrated mass and grain size distribution in the Eyjafjallajökull ash cloud, 12, 22587-22627,, doi:10.5194/acpd-12-22587-2012, 2012.

Devenish, B. J., Thomson, D. J., Marenco, F., Leadbetter, S. J., Ricketts, H., and Dacre, H.: A study of the arrival over the United Kingdom in April 2010 of the Eyjafjallajökull ash cloud using ground-based lidar and numerical simulations, Atmos. Environ., 48, 152-164, 2012.

Eckhardt, S., Prata, A. J., Seibert, P., Stebel, K., and Stohl, A.: Estimation of the vertical profile of sulfur dioxide injection into the atmosphere by a volcanic eruption using satellite column 
measurements and inverse transport modeling, Atmos. Chem. Phys., 8, 3881-3897, doi:10.5194/acp-8-3881-2008, 2008.

Flentje, H., Claude, H., Elste, T., Gilge, S., Köhler, U., PlassDülmer, C., Steinbrecht, W., Thomas, W., Werner, A., and Fricke, W.: The Eyjafjallajökull eruption in April 2010 - detection of volcanic plume using in-situ measurements, ozone sondes and lidar-ceilometer profiles, Atmos. Chem. Phys., 10, 10085-10092, doi:10.5194/acp-10-10085-2010, 2010.

Folch, A., Costa, A., and Basart, S.: Validation of the FALL3D ash dispersion model using observations of the 2010 Eyafjallajokull volcanic ash clouds, accepted, Atmos. Environ., 48, 165-183, 2011.

Gudmundsson, M. T., Thordarson, T., Hs̈kuldsson, Á., Laresen, G., Halldór, B., Prata, F. J., Oddsson, B., Magnússon, E., Hg̈nadt́tir T., Petersen, G. N., Hayward, C. L., Stevenson, J. A., and Jónsdóttir, I.: Ash generation and distribution from the April++May 2010 eruption of Eyjafallajkull, Iceland., Sci. Rep., 2, 572, doi:10.1038/srep00572, 2012.

Heffter, J.L. and Stunder, B.J.B., 1993: Volcanic Ash Forecast Transport and Dispersion (VAFTAD) Model. Weather Forecast, 8, 534-541.

Johnson, B. T., Turnbull, K. F., Dorsey, J., Baran, A. K.,Ulanowski, Z., Hesse, E., Cotton, R., Brown, P. R. A., Burgess, R., Capes, G., Webster,H. N., Woolley, A. M., Rosenberg, P. D. and Haywood, J. M.: In-situ observations of volcanic ash clouds from the FAAM aircraft during the eruption of Eyjafjallajökull in 2010, J. Geophys. Res., 117, D00U24, doi:10.1029/2011JD016760, 2011.

Jones, A. R., Thomson, D. J., Hort, M., and Devenish, B.: The U.K. Met Office's next-generation atmospheric dispersion model NAME III: in: Air Pollution Modelling and its Application XVII, edited by: Borrego, C. and Norman, A.-L., (Proceedings of the 27 NATO/CCMS International Technical Meeting on Air Pollution Modelling and its Application), Springer, 580-589, 2007.

Kristiansen, N. I., Stohl, A., Prata, A. J., Richter, A., Eckhardt, S., Seibert, P., Hoffmann, A., Ritter, C., Bitar, L., Duck, T. J., and Stebel, K.: Remote sensing and inverse transport modelling of the Kasatochi eruption sulphur dioxide cloud. J. Geophys. Res., 115, D00L16, doi:10.1029/2009/2009JD013286, 2010.

Kristiansen, N.I., Stohl, A., Prata, A. J., Bukowiecki, N., Dacre, H., Eckhardt, S., Henne, S., Hort, M. C., Johnson, B. T., Marenco, F., Neninger, B., Reitebuch, O., Seibert, P., Thomson, D. J., Webster, H. N., and Weinzierl, B.: Performance assessment of a volcanic ash transport model mini-ensemble used for inverse modeling of the 2010 Eyjafjallajökull eruption, J. Geophys. Res., 117, D00U11, doi:10.1029/2011JD016844, 2012.

Marenco, F., Johnson, B., Turnbull, K., Newman, S., Haywood, J., Webster H., and Ricketts, H.: Airborne lidar observations of the 2010 Eyjafjallajökull volcanic ash plume, J. Geophys. Res., 116, D00U05, doi:10.1029/2011JD016396, 2011.

Mastin, L. G.: A user-friendly one-dimensional model for wet volcanic plumes, Geochem. Geophys. Geosyst., 8, Q03014, doi:10.1029/2006GC001455, 2007.

Mastin, L.G., Guffianti, M., Servranckx, R., Webley, P. W., Barsottie, S., Dean, K., Denlinger, R., Durant, A., Ewert, J. W., Gardner, C. A., Holliday, A. C., Neri, A., Rose, W. I., Schneider, D., Siebert, L., Stunder, B., Swanson, G., Tupper, A., Volentik, A., and Waythomas, C. F.: A multidisciplinary effort to assign realistic source parameters to model of volcanic ash-cloud transport and dispersion during eruptions. Journal of Volcanology and
Geothermal Research : Special Issue on Volcanic Ash Clouds, edited by: Mastin, L. and Webley, P., 186, 10-21, 2009.

Petersen, G. N.: A short meteorological overview of the Eyjafjallajökull eruption 14 April-23 May 2010, Weather, doi:10.1002/wea.634, 2010.

Rauthe-Schöch, A., Weigelt, A., Hermann, M., Martinsson, B. G., Baker, A. K., Heue, K.-P., Brenninkmeijer, C. A. M., Zahn, A., Scharffe, D., Eckhardt, S., Stohl, A., and van Velthoven, P. F. J.: CARIBIC aircraft measurements of Eyjafjallajökull volcanic clouds in April/May 2010, Atmos. Chem. Phys., 12, 879-902, doi:10.5194/acp-12-879-2012, 2012.

Rose, W. I., Bluth, G. J. S., and Ernst, G. G. J.: Integrating retrievals of volcanic cloud characteristics from satellite remote sensors: a summary, Phil. Trans. R. Soc. Lond. A, 358, 1585-1606, 2000.

Schumann, U., Weinzierl, B., Reitebuch, O., Schlager, H., Minikin, A., Forster, C., Baumann, R., Sailer, T., Graf, K., Mannstein, H., Voigt, C., Rahm, S., Simmet, R., Scheibe, M., Lichtenstern, M., Stock, P., Rüba, H., Schäuble, D., Tafferner, A., Rautenhaus, M., Gerz, T., Ziereis, H., Krautstrunk, M., Mallaun, C., Gayet, J.F., Lieke, K., Kandler, K., Ebert, M., Weinbruch, S., Stohl, A., Gasteiger, J., Groß, S., Freudenthaler, V., Wiegner, M., Ansmann, A., Tesche, M., Olafsson, H., and Sturm, K.: Airborne observations of the Eyjafjalla volcano ash cloud over Europe during air space closure in April and May 2010, Atmos. Chem. Phys., 11, 2245-2279, doi:10.5194/acp-11-2245-2011, 2011.

Scollo, S., Folch, A., Coltelli, M. and Realmuto, V.J.: Threedimensional volcanic aerosol dispersal: A comparison between Multiangle Imaging Spectroradiaometer (MISR) data and numerical simulations. J. Geophys. Res., 115, D24210, doi:10.1029/2009JD013162, 2010.

Sparks, R. S., Bursik, J. M., Carey, S. N., Gilbert, J. S., Glaze, L. S., Siggurdsson, H. and Woods, A. W.: Volcanic Plumes, John Wiley and Sons, Chichester, UK, 1997.

Stohl, A., Prata, A. J., Eckhardt, S., Clarisse, L., Durant, A., Henne, S., Kristiansen, N. I., Minikin, A., Schumann, U., Seibert, P., Stebel, K., Thomas, H. E., Thorsteinsson, T., Tørseth, K., and Weinzierl, B.: Determination of time- and height-resolved volcanic ash emissions and their use for quantitative ash dispersion modeling: the 2010 Eyjafjallajökull eruption, Atmos. Chem. Phys., 11, 4333-4351, doi:10.5194/acp-11-4333-2011, 2011.

Thomas, H. E. and Prata, A. J.: Sulphur dioxide as a volcanic ash proxy during the April-May 2010 eruption of the Eyjafjallajökull volcano, Iceland, Atmos. Chem. Phys., doi:10.5194/acp11-6871-2011, 2011.

Turnbull, K., Johnson, B., Marenco, F. Haywood, J., Minikin, A., Weinzierl, B., Schlager, H., Schumann, U., Leadbetter, S., and Wooley, A.: A case study of observations of volcanic ash from the Eyjafjallajökull eruption: 1. In situ airborne observations. J. Geophys. Res., 117, D00U12, doi:10.1029/2011JD016688, 2012.

Webley, P. W., Atkinson, D., Collins, R. L., Dean, K., Fochesatto, J., Sassen, K., Cahill, C. F., Prata, A., Flynn, C. J., and Mizutani, K.: Predicting and validating the tracking of a volcanic ash cloud during the 2006 eruption of Mt Augustine Volcano, B. Am. Meteor. Soc., 89, 1647-1658, 2008.

Webley, P. W., Stunder, B. J. B. and Kean, K. G.: Preliminary sensitivity study of eruption source parameters for operational volcanic ash cloud transport and dispersion models - A case study of the August 1992 eruption of the Crater Peak vent, Mount Spurr, 
Alaska, J. Volcanol. Geotherm. Res., 186, 108-119, 2009.

Webster, H. N., Thomson, D. J., Johnson, B. T., Heard, I. P. C., Turnbull, K. F., Marenco, F., Kristiansen, N. I., Dorsey, J. R., Minikin, A., Weinzierl, B., Schumann, U., Sparks, S. S. J., Loughlin S. C., Hort, M., Leadbetter, S. J., Devenish, B., Manning, A. J., Witham, C., Haywood, J. M., and Golding, B.: Operational prediction of ash concentrations in the distal volcanic cloud from the 2010 Eyjafjallajokull eruption, J. Geophys. Res., 117, D00U08, doi:10.1029/2011JD016790, 2012.
Wen, S., and Rose, W. I.: Retrieval of sizes and total masses of particles in volcanic clouds using AVHRR bands 4 and 5. J Geophys. Res., 99, 5421-5431, 1994. 